\title{
Aneuploidy Rate, DNA Fragmentation, Tubulin and Centrin Content in Different Groups of Male Infertility
}

\author{
Özcan BUDAK* \\ Sakarya University, Faculty of Medicine, Histology and Embryology Department, Sakarya, Turkey \\ F.Süreyya CEYLAN \\ Kocaeli University, Faculty of Medicine, Histology and Embryology Department, Kocaeli, Turkey \\ Veysel TOPRAK \\ Private Tatvan Can Hospital Gynecology and Obstetrics, Bitlis 13200, Turkey \\ Ender Yalçınkaya \\ Ozel Adatip Hospital IVF Unit, Sakarya 54300, Turkey \\ Sema KURNAZ \\ Kocaeli University, Faculty of Medicine, Histology and Embryology Department, Kocaeli, Turkey \\ Murat KASAP \\ Department of Medical Biology, Kocaeli University Faculty of Health Sciences, Kocaeli 41300 \\ Eray ÇALIŞKAN \\ Bahcesehir University, Faculty of Medicine, Department of Obstetrics and Gynecology, Istanbul
}

\begin{abstract}
In this study, we aimed to compare DNA fragmentation ratios, centrosomal protein concentrations (centrin and tubulin) and numerical chromosomal abnormalities between four groups including asthenozoospermia, teratozoospermia, oligoasthenozoospermia and normozoospermia patients, and to emphasize the necessity of investigating genetic and protein content of the spermatozoa also in patients with a semen analysis within normal reference range. Evaluation of semen analysis of the patients was performed based on WHO 2010 criteria. As a result of the statistical analysis, it was observed that the sperm DNA fragmentation rate in the normozoospermia group $(6.50 \pm 3.46 \%)$ was significantly lower than those in the teratozoospermia $(19.69 \pm 9.86 \%)$ and oligoasthenoteratozoospermia group $(32.47 \pm 14.13 \%)(\mathrm{p}<0.001)$. For centrin and tubulin proteins, highest concentrations were observed in normozospermia group $(\mathrm{p}<0.05)$. When incidence of numerical abnormalities were compared between four groups, it was found that there were statistically significant differences between groups in terms of nullisomies $\mathrm{X}, \mathrm{Y}$ and 13 , and $21(\mathrm{p}<0.05)$. In conclusion, we suggest that abnormalities in semen parameters seem to be associated with chromosomal abnormalities; and sperm aneuploidy rate is also at a considerable level even in normozoospermic patients.
\end{abstract}

Keywords: DNA fragmentation, teratozoospermia, centrin, tubulin

DOI: $10.7176 / \mathrm{JMPB} / 68-04$

Publication date:September $30^{\text {th }} 2020$

\section{Introduction}

Male infertility is one of the important problems in humans and can be caused by different pathologies such as anatomical problems, infections, hormonal imbalances, chromosomal changes and gene anomalies. Although $30 \%$ of infertile men are affected by idiopathic oligoasthenoteratozoospermia, the cause of infertility is not fully known (Moretti, 2007). The first and basic test used to evaluate male infertility is standard semen analysis. It is used to evaluate all infertile men. In standard semen analysis, semen volume and $\mathrm{Ph}$, sperm concentration, mobility, morphology, sperm leukocyte count are evaluated parameters (Barrat,2011). Although standard semen analysis is routinely used in the evaluation of male infertility, the evaluated parameters may be insufficient in the exact separation of fertile and infertile men (Natali, 2011). Sperm DNA content is thought to be an additional parameter indicating semen quality and fertility potential (Aitken,2011). In studies performed to date, sperm chromatin defects and DNA fragments in infertile men have been shown to be higher than in fertile patients (Zini, 2001; Agarwal,2003; O Brien,2005; Schulte,2010; Omran,2013). Another point is the positive or negative effects of the nuclear quality of spermatozoon, especially in the success of assisted reproductive techniques applied in infertile couples. Studies have shown the relationship between semen parameters and sperm aneuploidy rates (Omran,2001). The susceptibility to aneuploid and diploid sperm production will increase the risk of chromosomal abnormal conceptus. As a result, this will lead to implant failure and/or pregnancy losses. It has been reported that most of 
the chromosome anomalies that occur after ICSI, which is one of the assisted reproductive techniques performed using the sperm of infertile men, are from paternal origin [Spano,2000,Mehdi,2006). Although high aneuploidy levels have been reported in fragmented DNA-containing spermatozoa of infertile cases with abnormal semen parameters (Brahem,2012), there are also studies showing that there is no relationship (Tandara,2014). The analysis of sperm motility plays a central role in the evaluation of male fertility because it is known that a high percentage of poorly motile or immotile sperm will not be able to fertilize. Studies have reported that decreased tubulin protein level is associated with poor sperm motility (Moretti, 2007; Chan, 2009; Bhagwat 2014).

The high rate of centrin expression in the neck regions of mammalian sperm cells has led to the concentration of research in the testicular tissue. As a result of centrin studies for gametes, some researchers have argued that the expression level of protein deficiencies may be related to infertility (Van Blerkom, 1996;Sun, 2002, Ayashti,2012).

In this study, we aimed to compare DNA fragmentation ratios, centrosomal protein concentrations (centrin and tubulin) and numerical chromosomal abnormalities between four groups including asthenozoospermia, teratozoospermia, oligoasthenoteratospermia and normozoospermia patients and to emphasize the necessity of investigating genetic and protein content of the spermatozoa also in patients with a semen analysis within normal reference range.

\section{Materials and Methods}

This study included men who admitted to Assisted Reproduction Unit of Kocaeli University Faculty of Medicine for infertility treatment. All men were informed about the aim and the design of the study. The study was based on voluntariness and all participants signed the written informed consent forms. This study was approved by Ethics Committee of Kocaeli University.

\subsection{Sample Selection and Patient Groups}

Sperm samples of normozoospermic $(n=20)$, asthenozoospermic $(n=35)$, teratozoospermic $(n=35)$, and oligoasthenoteratozoospermic $(n=30)$ patients were used in the study. Sperm samples were obtained after a 3-5 days of abstinence in Kocaeli University IVF Unit. Semen analyses were performed just after complete liquefaction of semen samples. Samples were classified into four groups based on WHO criteria (2010) such as normozoospermic, asthenozoospermic, oligoasthenoteratospermic, and teratozoospermic. Following this classification, semen samples were separated for TUNEL, immunohistochemistry, western blot and fluorescence in-situ hybridization (FISH) analyses. All sperm samples were fixed on the slides and stored at room temperature for DNA fragmentation analysis. FISH analysis was performed by fresh sperm samples. For Western Blot analyses, proteins were isolated from the spermatozoa and the proteins were stored at $-20^{\circ} \mathrm{C}$ until analysis.

We performed TUNEL method on four groups and we compared the results in the study. While comparing motility parameters of normospermic, oligoasthenospermic, teratozoospermic and asthenospermic sperm samples, we aimed to use centrin and tubulin proteins that are found in the centrosome.

\subsection{FISH technique}

FISH analyses in the study were performed with prenatal kit probes (Cytocell-aquaris, UK) described by Vahab Saadi et al (Vahab Saadi, 2010).

The preparations were examined under fluorescent microscope (Olympus BX61, USA) with the aid of suitable filters. At first, DAPI filter was used, and the appropriate metaphase screening was done. After the detection of appropriate metaphase screening, signals were shown by using filters with red and green spectra. 200 spermatozoa nuclei were assessed per probe for each slide. Signals were analyzed by a computer system (Applied Image Analyser (USA)) that was attached to fluorescence microscope and they were imaged by a camera (Sensys, Olympus, USA). At the end of the analyses, the ratios of numerical chromosomal abnormalities (disomies, nullisomies, diploidy, etc.) were explored and the results were evaluated.

\subsection{Western Blot}

Sperm cells were washed three times with ice-cold PBS and homogenized in lysis buffer containing $30 \mathrm{mM}$ Tris, $7 \mathrm{M}$ Urea, $2 \mathrm{M}$ Thiourea, $5 \mathrm{mM}$ Magnesium acetate, 4\% (w/v) CHAPS $\mathrm{pH} 8.5$, by using $0.1 \mathrm{~mm}$ glass beads in a mechanical disruption device (Bullet Blender; (Next Advance, USA). Homogenates were centrifuged at $15.000 \times \mathrm{g}$ for $30 \mathrm{~min}$ at $4{ }^{\circ} \mathrm{C}$ to remove cell debris. Protein concentrations were determined by Bradford Assay (BioRad, USA) and protein extracts were aliquoted, snap-frozen in liquid nitrogen and stored at $-80^{\circ} \mathrm{C}$.

Proteins were separated by $12 \%$ SDS-PAGE and transferred to a PVDF membrane (Roche, USA) using a Semi-Dry Transfer Cell (Bio-Rad, USA). The membrane was blocked in TBS-T buffer (Tris.HCl $25 \mathrm{mM} \mathrm{pH} \mathrm{7.2,}$ $\mathrm{NaCl} 150 \mathrm{mM}$, and $0.1 \%$ Tween 20 ) containing 5\% non-fat dry milk for $1 \mathrm{~h}$ at room temperature (RT) and subsequently incubated with primary antibody in TBS-T (in $2.5 \%$ non-fat dried milk in TBS-T) for $1 \mathrm{~h}$ at RT. The membrane was washed three times with TBS-T and then incubated with HRP-labelled secondary antibody (Bio$\mathrm{Rad}, \mathrm{USA}$ ) for $1 \mathrm{~h}$ at RT. Following three rinses with TBS-T, protein bands were visualized with an enhanced 
chemiluminescence detection system (Bio-Rad, USA). A monoclonal anti-tubulin antibody (SantaCruz, USA, sc8035) and a polyclonal anti-centrin anttibody (SantaCruz, USA, sc-365697) were used for blotting the membrane. Then the proteins were visualized with an ECL Plus Western blotting detection system (GE Healthcare). The bands were quantitated by using Quantity One 1D image analysis software (Bio-Rad, USA).

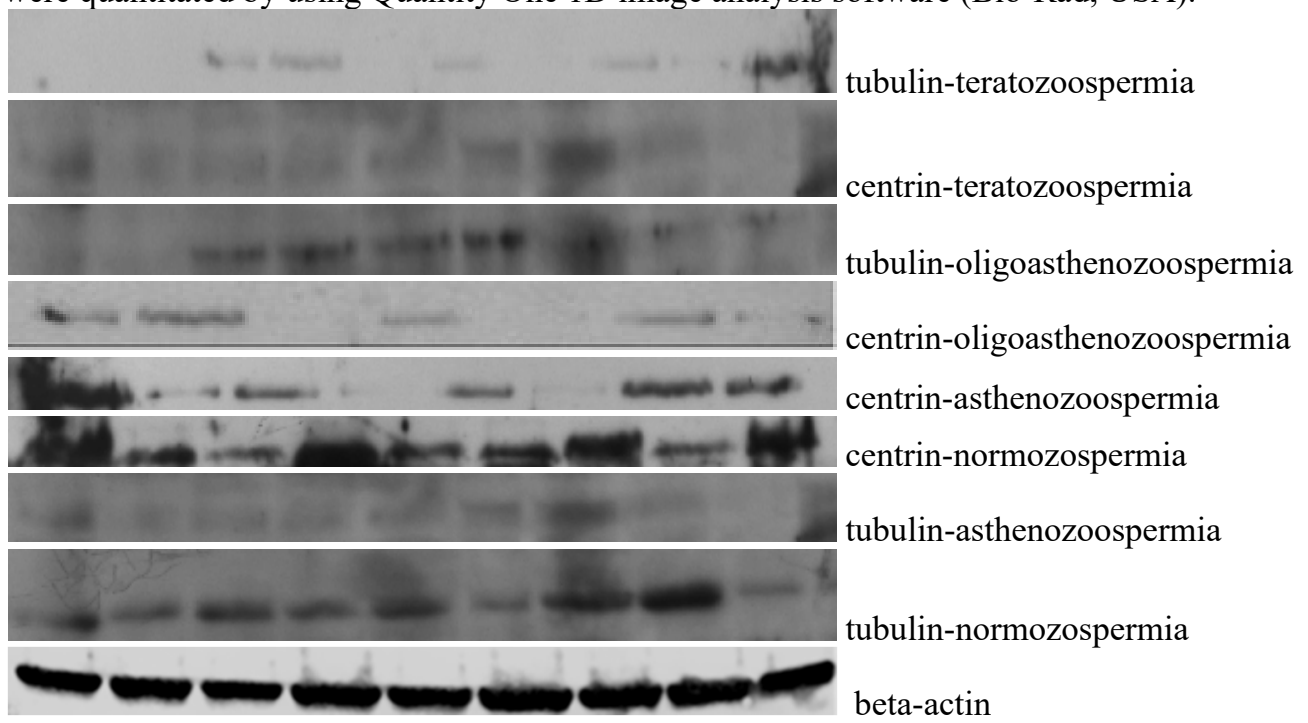

Picture 1. Western blot bands belonging to the normozoospermia, astenozoospermia, teratozoospermia and oligoastenothozoospermia against centrin and tubulin antibodies.

\subsection{Immunofluorescence staining}

Sperm samples were placed on glass cover slips and were fixed with formaldehyde and permeabilized with $0.5 \%$ Triton X-100 as described in Kasap et al., (Kasap, 2011). Cover slips were mounted in Mowiol before analysis. Monoclonal antibodies were from Santa Cruz Biotech (USA). Non-cross reactive Texas Red secondary antibody and DAPI was from Jackson ImmunoResearch (USA). Cells were observed with an inverted Olympus CKX41 (USA) microscope with an appropriate filter set.

\subsection{TUNEL Method}

TUNEL method was applied with the references of Millipore, ApotTag- Plus Fluorescein In Situ Apoptosis Detection Kit S7111 (USA) (Park, 2006). The preparations were photographed under fluorescence microscope (Olympus BX51); a mean of 200 cells were counted per slide and \% percentage was calculated by Park at al., (Park, 2006). While signals could not be taken from healthy cells, green signals were obtained from apoptotic sperm cells. Since DAPI was used, healthy sperms were observed in blue color. Since a common filter was used, apoptotic cells were observed on blue background with their green signals.

\section{Statistical Analysis}

Variables were presented as mean $+/-$ SD and median (25th -75 th percentiles). Statistical assessment was done by SPSS 20.0 (SPSS Inc., Chicago, IL, USA) package program. Compliance of numerical variables to normal distribution was tested by Kolmogorov-Smirnov Test. Differences between groups were tested by Kruskal-Wallis, Dunn's Multiple comparison test and Mann Whitney U test for the variables that were not showing normal distribution. $\mathrm{p}<0.05$ was considered as statistically significant.

\section{Results}

As a result of the one-way analysis of variance (One Way ANOVA) performed to compare age, volume, sperm count, sperm progression, +4 motion, +3 motion and morphology values by groups, there was no significant difference between the groups according to age and volume. There was a significant difference in terms of motility, sperm progression, +4 motion, +3 motion and morphology (Table 1$)$. 
Table 1. Comparison of spermiogram results by groups

\begin{tabular}{|l|l|l|l|l|l|}
\hline & Group 1 & Group 2 & Group 3 & Group 4 & $\mathrm{p}$ \\
\hline Age & $31,75 \pm 5.74$ & $31,03 \pm 5.69$ & $31,57 \pm 5.59$ & $32,83 \pm 6.72$ & $>0.05$ \\
\hline Volume (ml) & $3,05 \pm 1.17$ & $3,41 \pm 1.75$ & $3,69 \pm 1.41$ & $2,57 \pm 1.13$ & $>0.05$ \\
\hline Sperm Count (mil/ml) & $78,40 \pm 48.77$ & $41,76 \pm 27.19$ & $45,91 \pm 33.18$ & $8,81 \pm 2.48$ & $<0.001$ \\
\hline Sperm Motility (\%) & $59,55 \pm 8.56$ & $29,31 \pm 11.55$ & $55,60 \pm 11.30$ & $12,67 \pm 4.13$ & $<0.001$ \\
\hline Sperm Progression (\%) & $48,70 \pm 10.90$ & $21,57 \pm 10.00$ & $42,80 \pm 12.36$ & $9,27 \pm 3.28$ & $<0.001$ \\
\hline+4 motil sperm (\%) & $6,75 \pm 5.20$ & $1,00 \pm 2.03$ & $4,14 \pm 4.92$ & $1,40 \pm 2.04$ & $<0.001$ \\
\hline+3 motil sperm (\%) & $41,00 \pm 9.79$ & $20,26 \pm 9.73$ & $38,66 \pm 12.20$ & $7,87 \pm 2.70$ & $<0.001$ \\
\hline Morphology (\%) & $8,65 \pm 2.11$ & $5,40 \pm 1.38$ & $0,49 \pm 0.74$ & $0,33 \pm 0.48$ & $<0.001$ \\
\hline
\end{tabular}

Group 1: Normozoospermia

Group 2: Asthenozoospermia

Group 3: Teratozoospermia

Group 4: Oligoasthenoteratozoospermia

When the TUNEL percentage reflecting the sperm fragmentation rate was examined, the difference between the groups was found to be statistically significant $(p<0.001)$. As a result of the analysis, it was observed that the sperm DNA fragmentation ratio in oligoasthenoteratozoospermia group was higher than the other groups. In our study, sperm fragmentation ratios were found as $6.50 \pm 3.46 \%$ in normozoospermia group, $11.09 \pm 6.07 \%$ in astheozoospermia group, $19.69 \pm 9.86 \%$ in teratozoospermia and $32.47 \pm 14.13 \%$ in oligoasthenoteratozoospermia group; and the difference was found to be statistically significant $(\mathrm{p}=0.000)$ (Table 2$)$.

Table 2. Results of TUNEL, Western-blot and immunofluorescence staining among all groups

\begin{tabular}{|l|l|l|l|l|l|}
\hline & Group 1 & Group 2 & Group 3 & Group 4 & $\mathrm{p}$ \\
\hline TUNEL Percent & $6,50 \pm 3.46$ & $11,09 \pm 6.07$ & $19,69 \pm 9.86$ & $32,47 \pm 14.13$ & $<0.001^{\mathrm{A}}$ \\
\hline Western tubulin & $9,29 \pm 9.50$ & $4,09 \pm 3.20$ & $1,20 \pm 0.68$ & $0,45 \pm 0.27$ & $<0.001^{\mathrm{B}}$ \\
\hline Western centrin & $19,61 \pm 16.51$ & $2,28 \pm 1.51$ & $1,10 \pm 0.53$ & $0,49 \pm 0.32$ & $<0.001^{\mathrm{C}}$ \\
\hline
\end{tabular}

A; When group 1 and group 3 and 4 are compared ( $<<0.001, p<0.001$, respectively)

When group 2 and group 3 and 4 are compared $(\mathrm{p}=0.002, \mathrm{p}<0.001$, respectively)

When group 3 and group 4 are compared $(\mathrm{p}<0.001)$

B; When group 1 and group 2,3 and 4 are compared ( $<0.001, p<0.001, p<0.001$, respectively)

When group 2 and group 3 and 4 are compared $(\mathrm{p}=0.031, \mathrm{p}<0.005$, respectively)

$\mathrm{C}$; When group 1 and group 3 and 4 are compared ( $<0.001, \mathrm{p}<0.001, \mathrm{p}<0.001$, respectively)

The evaluation results of Western tubulin and western centrin levels, which have an important place in sperm motility and embryogenesis, are presented in Table 2. As expected, the lowest values were observed in Group 4. This difference between the groups was found to be significant according to the One Way ANOVA test $(\mathrm{p}<0.001)$.

FISH test was used to investigate whether there is chromosomal anomaly or not in the spermiogram test. The data obtained are presented in Table 3. As expected, chromosomal anomaly was mostly observed in Group 4 patients. In the evaluation made in terms of Nullism X, Nullism Y and Nullism 13, ve significant difference was found between the groups. At the end of FISH analyses, no significant differences were found between group in terms of monosomies X, Y, 13, 18 and 21 (Table 3). There were no statistically significant differences between groups in terms of disomies $\mathrm{X}, \mathrm{Y}, 13,18$ and 21 (Table 3).

Table 3. FISH results of the study groups

\begin{tabular}{|l|l|l|l|l|l|}
\hline & Group 1 $(\mathrm{n}=20)$ & Group 2 $(\mathrm{n}=35)$ & Group 3 $(\mathrm{n}=35)$ & Group 4 $(\mathrm{n}=30)$ & $\mathrm{p}$ \\
\hline Nullisomi X $(\mathrm{n})$ & $4(\% 20)$ & $11(\% 31.4)$ & $18(\% 51.4)$ & $24(\% 80)$ & $<0.001$ \\
\hline Nullisomi Y $(\mathrm{n})$ & $1(\% 5)$ & $6(\% 17.1)$ & $11(\% 31.4)$ & $16(\% 53.3)$ & 0.001 \\
\hline Nullisomi 13 $(\mathrm{n})$ & $3(\% 15)$ & $15(\% 42.9)$ & $19(\% 54.3)$ & $17(\% 56.7)$ & 0.017 \\
\hline Nullisomi 18 $(\mathrm{n})$ & $4(\% 20)$ & $6(\% 17.1)$ & $10(\% 28.6)$ & $11(\% 36.7)$ & 0.295 \\
\hline Nullisomi 21 $(\mathrm{n})$ & $2(\% 10)$ & $10(\% 28.6)$ & $11(\% 31.4)$ & $10(\% 33.3)$ & 0.275 \\
\hline Monosomi X (n) & $4(\% 20)$ & $8(\% 22.9)$ & $14(\% 40)$ & $12(\% 40)$ & 0.204 \\
\hline Monosomi Y (n) & $2(\% 10)$ & $9(\% 25.7)$ & $8(\% 22.9)$ & $8(\% 26.7)$ & 0.512 \\
\hline Trisomi 13 (n) & $4(\% 20)$ & $6(\% 17.1)$ & $14(\% 40)$ & $11(\% 36.7)$ & 0.108 \\
\hline Trisomi 21 $(\mathrm{n})$ & $2(\% 10)$ & $5(\% 14.3)$ & $14(\% 40)$ & $14(\% 46.7)$ & 0.003 \\
\hline Monosomi 13 $(\mathrm{n})$ & $2(\% 10)$ & $7(\% 20)$ & $8(\% 22.9)$ & $9(\% 30)$ & 0.404 \\
\hline Monosomi 18 $(\mathrm{n})$ & $1(\% 5)$ & $5(\% 14.3)$ & $7(\% 20)$ & $7(\% 23.3)$ & 0.342 \\
\hline Monosomi 21 $(\mathrm{n})$ & $1(\% 5)$ & $7(\% 20)$ & $9(\% 25.7)$ & $8(\% 26.7)$ & 0.243 \\
\hline Disomi X $(\mathrm{n})$ & $3(\% 15)$ & $7(\% 20)$ & $11(\% 31.4)$ & $7(\% 23.3)$ & 0.517 \\
\hline Disomi $\mathrm{Y}(\mathrm{n})$ & $3(\% 15)$ & $10(\% 28.6)$ & $10(\% 28.6)$ & $7(\% 23.3)$ & 0.662 \\
\hline
\end{tabular}




\begin{tabular}{|l|l|l|l|l|l|}
\hline & Group 1 $(\mathrm{n}=20)$ & Group 2 $(\mathrm{n}=35)$ & Group 3 $(\mathrm{n}=35)$ & Group 4 $(\mathrm{n}=30)$ & $\mathrm{p}$ \\
\hline Disomi 13 $(\mathrm{n})$ & $2(\% 10)$ & $8(\% 22.9)$ & $14(\% 40)$ & $8(\% 26.7)$ & 0.099 \\
\hline Disomi 18 $(\mathrm{n})$ & $3(\% 15)$ & $8(\% 22.9)$ & $7(\% 20)$ & $10(\% 33.3)$ & 0.444 \\
\hline Disomi 21 $(\mathrm{n})$ & $6(\% 30)$ & $9(\% 25.7)$ & $17(\% 48.6)$ & $8(\% 26.7)$ & 0.153 \\
\hline
\end{tabular}

When the concentrations of western blot bands belonging to the normozoospermia, astheonozoospermia, teratozoospermia and oligoasthenoteratozoospermia groups were measured against centrin and tubulin antibodies, the bands belonging to the normozoospermia group were higher than the other three groups (Figure 2). As a result of the statistical analysis between the groups, the same result was obtained.
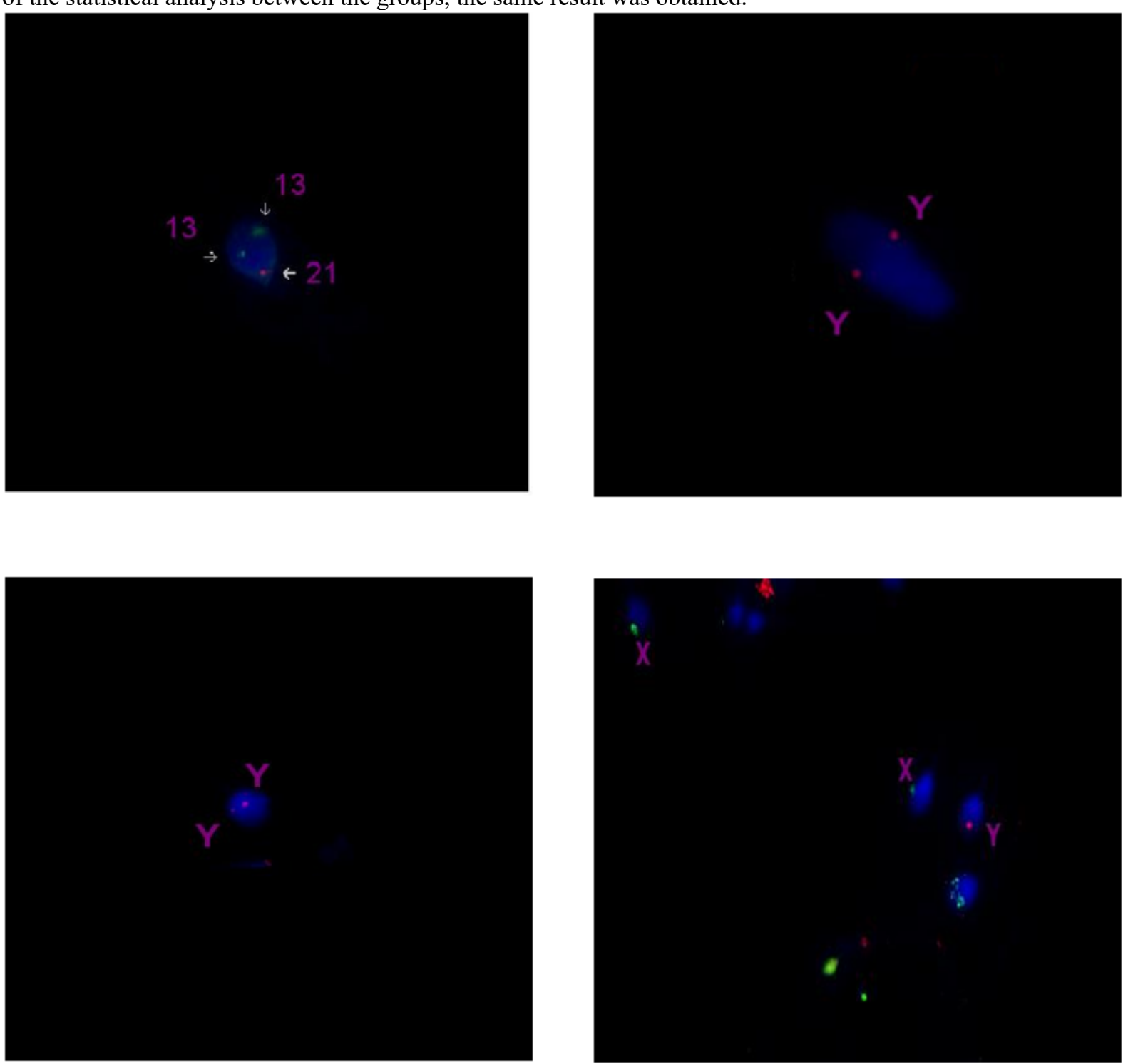

Fig.2-Examples of sperm fluorescent in situ hybridization (FISH) visualized under a fluorescence microscope. Top left: Teratozoopermia group, Sperm with chromosome 13 disomy, Top right: Asthenozoospermia group, sperm with chromosome Y disomy, Bottom left: Oligoastenoteratospermia group, sperm with sex chromosome Y disomy and Bottom right: normozoospermia group, normal sperm. 
In the immunofluorescence staining against the tubulin and centrin proteins concentrated in the sperm neck region especially between the normozoospermia group and oligoastenothetospermia groups, the differences between the staining areas are noteworthy. We observed that the presence of tubulin and centrin protein in the neck region was higher in the normozoospermia group (Figure 3).
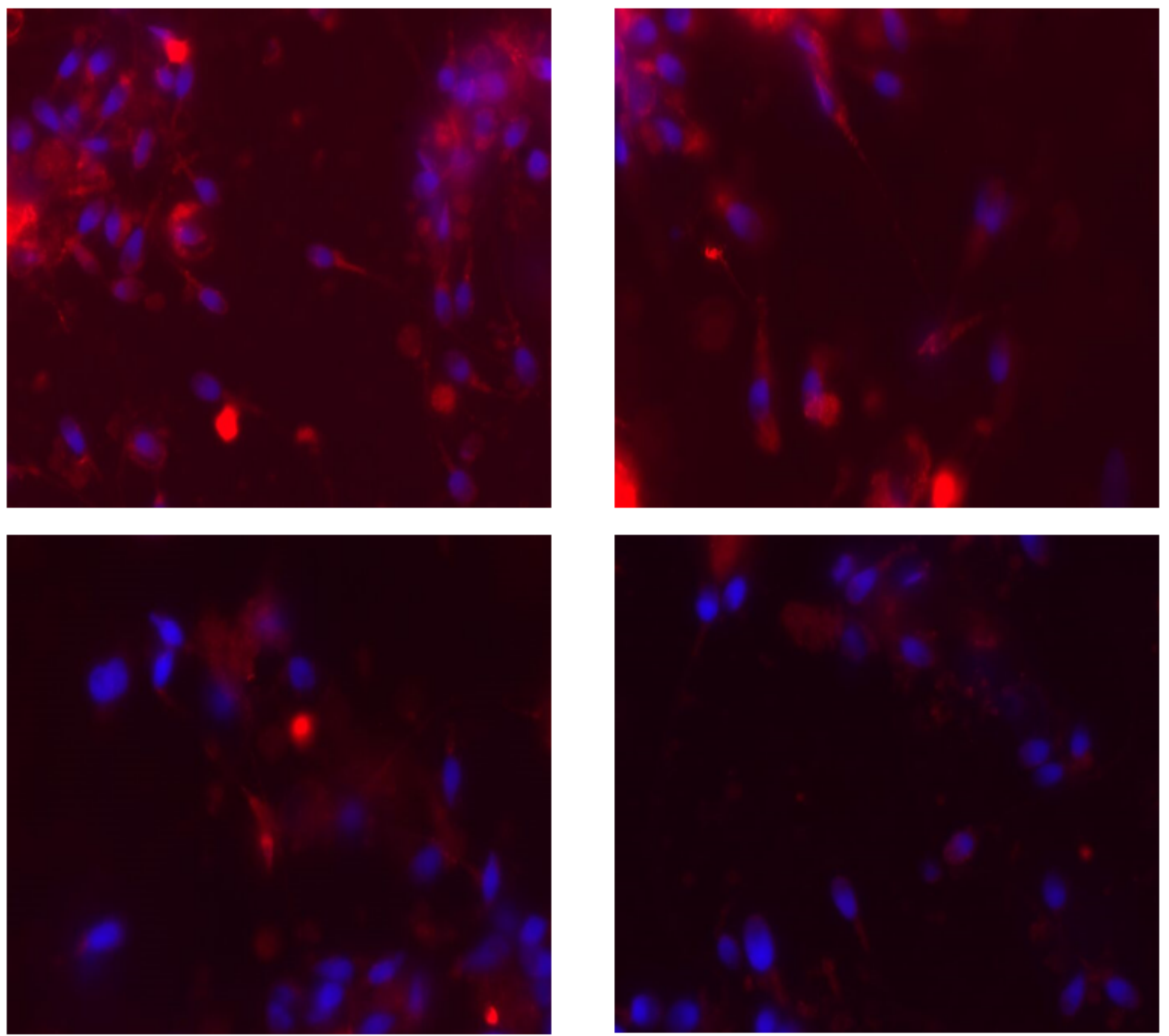

Fig.3-Immunofluorescent localization of centrin and tubulin in human sperm. Blue, DNA; and red, functional centrosomal proteins (tubulin or centrin). Top left: Oligoastenoteratospermia group Tubulin antibody. Top right: Oligoastenoteratospermia group Centrin antibody. Bottom left: Normozoospermia group Tubulin antibody. Bottom right: Normozoospermia group Centrin antibody. Neck and flagella regions are more intense stained in normozoospermic group than Oligoastenoteratospermia sperm samples.

\section{Discussion}

The integrity of the centrosome of spermatozoa was reported to be crucial for successful fertilization and subsequent embryo development in humans (Schatten,2009). An association between sperm centriole abnormalities and sperm motility defects was found in infertile men (Schatten, 2009; Rawe,2002). In recent immunostaining studies, dominant source of centrosome was found as spermatozoa [Manandhar2005; , Sun,2007). Thus, researchers have observed ICSI procedures in different species in order to understand the functions of sperm centrosomes . At the end of these studies, they found that centrosome could affect sperm motility and fertilization capability. Centrosomes are features that are inherited from the father. While human oocytes do not contain centrosomes, sperm cells have two centrosomes. The importance of centrosomes for fertilization and embryo development is its ability to contribute to the organization of female and male pronuclei. Therefore; any defects or irregularities in the centrosome structure will directly give damage to fertilization and subsequent embryo development (Schatten2008; Terada,2008).

Centrosomal protein alpha tubulin constitutes the functional part of microtubule organization center and plays 
the major role in the formation of centrosome structure (Moritz,1998). Siemrly et al (1999) have observed that alpha and gamma tubulin was genetically inherited from one parent during fertilization. During the measurements performed with ELISA, it was observed that the amount of centrin was also more in control group compared to oligoasthenozoospermic group; thus, it seems that that centrin is associated with motility (Hinduja,2010). Centrin is a Ca-dependent protein and it plays a role during detachment of flagellar structure at axoneme movement; in other words, in the generation of motility. Moreover, it has a role in fertilization. Besides contributing to the functional roles of the organelles, centrin also has an importance for sperm tail (Laoukili,2000). Nakamura et al (2005) have observed abnormal centrin concentrations in asthenozoospermic men. This was mostly found in the sperm cells that show a bad tail organization (Nakamura,2005;- Moudjou,1994). When sperm tail structures of normozoospermic and asthenozoospermic patients were examined in our study, it was observed that less gamma and alpha tubulin structures were present in the sperm tail structures of asthenozoospermic patients compared to normal group in western blot analysis. The results of our study were similar to the studies in the literature.

Several reports have studied the association between sperm DNA damage and seminal parameters and they have conflicting results (Lopes S, 1998; Muratori ,2000; Gandini ,2000; Zini ;2002; - Sergerie M,2002). In some of them, sperm DNA fragmentation was found to be correlated with some seminal parameters (Aitken , 2010; Mehdi M ,2009; Cohen-Bacrie ,2009;- Benchaib M ,2007; Said TM,2007). Regarding the relationship between sperm DNA damage and semen quality, Nassira et al (2011) have found that DNA fragmentation was higher in asthenozoospermic patients compared to control ones. DNA fragmentation was found in dyspermic semen samples more than normospermic ones (Mehdi M, 2009). Piasecka (2007) have found that the percentage of TUNELpositive cells was significantly higher in patients whose semen had a poor motility as compared to men with normal sperm motility. Varghese et al (2009) have emphasized the increase in the incidence of sperm DNA fragmentation in male factor infertility and its effects on the outcomes of assisted reproductive treatments. Qui et al (2008) also found a significant relationship between sperm DNA fragmentation and sperm density, sperm motility and abnormal sperm. However, some researchers did not find a relationship between DNA fragmentation and sperm parameters [Santiso R 2010, De Iuliis, 2009;De Iuliis,2010; Aitken RJ, ,2010).

Mehdi at al. (2009) have found that the difference in sperm DNA fragmentation was not significant between asthenozoospermic and the normospermic men. The patients presenting with teratozoospermia showed a significantly higher percentage of DNA fragmentation compared to the normospermic group (Mehdi, 2009). They also concluded that the defects in sperm parameters were associated with an increase in DNA fragmentation; and this association was strictly related to atypical forms of spermatozoa found in the semen. Our results were similar to the findings of Mahdi et al. The percentage of sperm DNA fragmentation was found highest in teratozoospermi group, and it was followed by asthenozoospermic and normozoospermic groups. The patients in teratozoospermia group constituted a significantly higher difference in terms of sperm DNA fragmentation.

There are many studies focusing on sperm chromosomal abnormalities in the literature; but, some of them have conflicting results. In some previous studies, higher aneuploidy rates were reported in spermatozoa of males with decreased seminal parameters (Hristova R, 2002; Tempest , 2004; Machev ,2005; Miharu N ,2005; Rives ,2005; Tang SS ,2010). A majority of results indicated an association between oligozoospermia and aneuploidy rates; but, no such a clear association was found between aneuploidy rates and asthenozoospermia or teratozoospermia patients (Tempest, 2004; Machev , 2005; Miharu N ,2005; Rives ,2005; Tang SS ,2010).

Walter at al (2000) evaluated the correlation between the total abnormality rates and three sperm parameters: concentration of spermatozoa, percentage of spermatozoa with progressive motility and percentage of spermatozoa with normal morphology. The total abnormality rates for chromosomes 13 and 21 and for chromosomes $18, \mathrm{X}$ and $\mathrm{Y}$ had been tremendously and inversely correlated with the concentration of spermatozoa and with the complete progressive motility. Such a correlation was with the normal morphology and in the other groups with all the three sperm parameters considered (Walter 2000). The risk of a chromosomal aneuploidy in spermatozoa seems to be inversely correlated with sperm concentration and total progressive motility (Walter ,2000).

In whole, $40 \%$ of guys with usual spermatozoa density and motility had abnormal sperm aneuploidy in all the chromosomes analyzed. Men with abnormal spermatozoa density and motility had a greater proportion of sperm sex chromosome aneuploidy than men with normal density, motility. Men with normal strict morphology had lower rates of sex chromosome and sperm aneuploidy than men with abnormal strict morphology. The percentage of aneuploid spermatozoa was magnificently higher in patients with oligozoospermia comparing with the ones with astheno- and teratozoospermia. There is a significant difference in content of spermatozoa with cytoplasmic drop depending on the FISH result (Fes'kov AM,2013).

For motility problems, in the review of Sarrate et al. (2010) there was no correlation between low motility and increased aneuploidy. Other resarchs had showed a fair correlation between the two parameters (Aran B,1998; , Vegetti W,2000). Concerning morphology, in sufferers with distinctive varieties of teratozoospermia, most experiences exhibit a 2- four-fold broaden of intercourse chromosome disomy and a 2-three-fold expand of aneuploidy (Vegetti W,2000; Gole LA ,2001; Templado C,2001; Brahem S,2011). However, Sarrate et al. (2010) did not find a correlation between teratozoospermia and aneuploidy even when analysing the 17 exclusively 


\section{teratozoospermic patients}

In our study, When incidence of numerical abnormalities were compared between four groups, it was found that there were statistically significant differences between groups in terms of nullisomies $\mathrm{X}, \mathrm{Y}$ and 13, disomy 13 and trisomies 13 and 21. The percentage of aneuploid spermatozoa was magnificently higher in patients with teratozoospermic group comparing with the ones with astheno- and normozoospermic group and the percentage of sperm aneuploidy rate was found lowest in normozoospermic group. We have found similar results to the study of literature. We found an association between chromosomal abnormalities in sperm morphology and sperm velocity parameters.

\section{Conclusions}

The fact we would like to emphasize in our study is that sperm chromosomal aneuploidies and DNA fragmentation can be found also in the spermatozoa of normozoospermic men at a considerable level. This reveals that spermatozoa of normozoospermic men should also be subjected to detailed investigation as much as male infertility indications such as teratozoospermia, asthenozoospermia and azospermia. Moreover; these possible diagnostic biomarkers will increase our understanding about the possible causes in unexplained infertility cases and repeated misconceptions.

\section{References}

Agarwal, A., \& Said, T. M. (2003). Role of sperm chromatin abnormalities and DNA damage in male infertility. Human reproduction update, 9(4), 331-345.

Aitken RJ, Curry BJ: Redox Regulation of Human Sperm Function: From the Physiological Control of Sperm Capacitation to the Etiology of Infertility and DNA Damage in the Germ Line. Antioxid Redox Signal 2010.

Aitken RJ, De Iuliis GN, Finnie JM, Hedges A, McLachlan RI: Analysis of the relationships between oxidative stress, DNA damage and sperm vitality in a patient population: development of diagnostic criteria. Hum Reprod 2010, 25:2415-2426.

Aitken RJ, De Iuliis GN, Finnie JM, Hedges A, McLachlan RI: Analysis of the relationships between oxidative stress, DNA damage and sperm vitality in a patient population: development of diagnostic criteria. Hum Reprod 2010, 25:2415-2426.

Aitken, R. J., \& Henkel, R. R. (2011). Sperm cell biology: current perspectives and future prospects. Asian Journal of Andrology, 13(1), 3-5

Aran B, Blanco J, Vidal F, Vendrell JM, Egozcue S, Barri PN, Egozcue J, Veiga A. Screening for abnormalities of chromosomes X, Y and 18 and for diploidy in spermatozoa from infertile men participating in an in vitro fertilization-intracytoplasmic sperm injection program. Fertil Steril 1999;72:696-701.

Avasthi, P., Scheel, J. F., Ying, G., Frederick, J. M., Baehr, W., \& Wolfrum, U. (2013). Germline deletion of Cetn1 causes infertility in male mice. J Cell Sci, 126(14), 3204-3213.

Barratt, C. L., Mansell, S., Beaton, C., Tardif, S., \& Oxenham, S. K. (2011). Diagnostic tools in male infertility the question of sperm dysfunction. Asian journal of andrology, 13(1), 53.

Benchaib M, Lornage J, Mazoyer C, Lejeune H, Salle B, François Guerin J: Sperm deoxyribonucleic acid fragmentation as a prognostic indicator of assisted reproductive technology outcome. Fertil Steril 2007, 87:93-100.

Bhagwat, S., Dalvi, V., Chandrasekhar, D., Matthew, T., Acharya, K., Gajbhiye, R., ... \& Parte, P. (2014). Acetylated $\alpha$-tubulin is reduced in individuals with poor sperm motility. Fertility and sterility, 101(1), 95-104.

Brahem S, Elghezal H, Ghedir H, landolsi H, Amara A, Ibala S, Gribaa M, Saad A, Mehdi M. Cytogenetic and molecular aspects of absolute teratozoospermia: Comparison between polymorphic and monomorphic forms. Urology 2011a;78:1313-1319.

Brahem, S., Jellad, S., Ibala, S., Saad, A., \& Mehdi, M. (2012). DNA fragmentation status in patients with necrozoospermia. Systems biology in reproductive medicine, 58(6), 319-323.

Chan, C. C., Shui, H. A., Wu, C. H., Wang, C. Y., Sun, G. H., Chen, H. M., \& Wu, G. J. (2009). Motility and protein phosphorylation in healthy and asthenozoospermic sperm. Journal of Proteome Research, 8(11), 5382-5386.

Chemes EH, Rawe YV. Sperm pathology: A step beyond descriptive morphology. Origin, characterization and fertility potential of abnormal sperm phenotypes in infertile men. Hum Reprod Update. 2003;9:405-28.

Cohen-Bacrie P, Belloc S, Ménézo YJ, Clement P, Hamidi J, Benkhalifa M: Correlation between DNA damage and sperm parameters: a prospective study of 1,633 patients. Fertil Steril 2009, 91:1801-1805.

De Iuliis GN, Thomson LK, Mitchell LA, Finnie JM, Koppers AJ, Hedges A, Nixon B, Aitken RJ: DNA damage in human spermatozoa is highly correlated with the efficiency of chromatin remodeling and the formation of 8-hydroxy-2'-deoxyguanosine, a marker of oxidative stress.Biol Reprod 2009, 81:517-524.

Fes'kov AM, Zhilkova ES, Bezpechnaia IM, Somova EV, Fes'kov VA. Correlation of the spermatozoa morphological anomaly with the presence of aneuploidies in its nuclei in the patients with astheno-, oligo- 
and teratozoospermia. Tsitol Genet. 2013 Mar-Apr;47(2):66-9.

Gandini L, Lombardo F, Paoli D, Caponecchia L, Familiari G, Verlengia C, Dondero F, Lenzi A: Study of apoptotic DNA fragmentation in human spermatozoa. Hum Reprod 2000, 15:830-839.

Gole LA, Wong PF, Ng PL, Wang XQ, Ng SC, Bongso A. Does sperm morphology play a significant role in increased sex chromosomal disomy? A comparison between patients with teratozoospermia and OAT by FISH†. J Androl 2001;22:759-763.

Hinduja I, Baliga NB, Zaveri K. Correlation of human sperm centrosomal proteins with fertility. J Hum Reprod Sci. 2010 May;3(2):95-101

Hristova R, Ko E, Greene C, Rademaker A, Chernos J \& Martin R 2002 Chromosome abnormalities in sperm from infertile men with asthenoteratozoospermia.Biology of Reproduction 66 1781-1783.

Kasap, M., Karaoz, E., Akpinar, G., Aksoy, A., \& Erman, G. (2011). A unique Golgi apparatus distribution may be a marker for osteogenic differentiation of hDP-MSCs. Cell biochemistry and function, 29(6), 489-495.

Laoukili J1, Perret E, Middendorp S, Houcine O, Guennou C, Marano F, Bornens M, Tournier F. Differential expression and cellular distribution of centrin isoforms during human ciliated cell differentiation in vitro. $\mathbf{J}$ Cell Sci. 2000 Apr;113 ( Pt 8):1355-64.

Lopes S, Sun J, Jurisicova A, Meriano J, Casper RF: Sperm deoxyribonucleic acid fragmentation is increased in poor-quality semen samples and correlates with failed fertilization in intracytoplasmic sperm injection. Fertil Steril 1998, 69:528-532.

Machev N, Gosset P, Warter S, Treger M, Schillinger M \& Viville S 2005 Fluorescence in situ hybridization sperm analysis of six translocation carriers provides evidence of an interchromosomal effect. Fertility and Sterility 84 365-373.

Manandhar G., Schatten H., Peter Sutovsky P., Centrosome Reduction During Gametogenesis and Its Significance1 Biology Of Reproduction 2005;72, 2-13

Mehdi M, Khantouche L, Ajina M, Saad A: Detection of DNA fragmentation in human spermatozoa: correlation with semen parameters. Andrologia 2009, 41:383-386.

Mehdi, M., Smatti, B., Saad, A., Guerin, J., \& Benchaib, M. (2006). Analysis by fluorescence in situ hybridization (FISH) of the relationship between gonosomic aneuploidy and the results of assisted reproduction in men with severe oligozoospermia. Andrologia, 38(4), 137-141.

Miharu N. (2005) Chromosome abnormalities in sperm from infertile men with normal somatic karyotypes: oligozoospermia. Cytogenetic and Genome Research 111 347-351.

Moretti, E., Scapigliati, G., Pascarelli, N. A., Baccetti, B., \& Collodel, G. (2007). Localization of AKAP4 and tubulin proteins in sperm with reduced motility. Asian journal of andrology, 9(5), 641-649.

Moritz M, Zheng Y, Alberts BM, Oegema K. Recruitment of the gamma-tubulin ring complex to Drosophila saltstripped centrosome scaffolds.J Cell Biol. 1998 Aug 10;142(3):775-86.

Moudjou M, Bornens M. A Laboratory Handbook Cell Biol. 1994. Isolation of centrosomes from cultured animal cells; pp. 594-604.

Muratori M, Piomboni P, Baldi E, Filimberti E, Pecchioli P, Moretti E, Gambera L, Baccetti B, Biagiotti R, Forti G, Maggi M: Functional and ultrastructural features of DNA-fragmented human sperm. J Androl 2000, 21:903-912.

Nakamura S, Terada Y, Horiuchi T, Emuta C, Murakami T, Yaegashi N, Okamura K. Analysis of the human sperm centrosomal function and the oocyte activation ability in a case of globozoospermia, by ICSI into bovine oocytes.Hum Reprod. 2002 Nov;17(11):2930-4.

Nakamura S1, Terada Y, Rawe VY, Uehara S, Morito Y, Yoshimoto T, Tachibana M, Murakami T, Yaegashi N, Okamura K. A trial to restore defective human sperm centrosomal function. Hum Reprod. 2005 Jul;20(7):1933-7. Epub 2005 Apr 14.

Nassira Zribi, Nozha Feki Chakroun, Henda Elleuch, Fatma Ben Abdallah, Afifa Sellami Ben Hamida, Jalel Gargouri3, Faiza Fakhfakh1 and Leila Ammar Keskes1,2 Sperm DNA fragmentation and oxidation are independent of malondialdheyde. Reproductive Biology and Endocrinology 2011, 9:47

Natali, A., \& Turek, P. J. (2011). An assessment of new sperm tests for male infertility. Urology, 77(5), $1027-$ 1034.

O’Brien, J., \& Zini, A. (2005). Sperm DNA integrity and male infertility. Urology, 65(1), 16-22.

Omran, H. M., Bakhiet, M., \& Dashti, M. G. (2013). DNA integrity is a critical molecular indicator for the assessment of male infertility. Molecular medicine reports, 7(5), 1631-1635.

Park, W. S., Sung, D. K., Kang, S., Koo, S. H., Kim, Y. J., Lee, J. H., \& Lee, M. (2006). Neuroprotective effect of cycloheximide on hypoxic-ischemic brain injury in neonatal rats. Journal of Korean medical science, 21(2), 337-341.

Piasecka M1, Gaczarzewicz D, Laszczyńska M, Starczewski A, Brodowska A. Flow cytometry application in the assessment of sperm DNA integrity of men with asthenozoospermia. Folia Histochem Cytobiol. 2007;45 Suppl 1:S127-36. 
Qiu Y, Wang L, Zhang L, Yang D, Zhang A, Yu J. Analysis of sperm chromosomal abnormalities and sperm DNA fragmentation in infertile males 2008 Dec;25(6):681-5.

Rawe VY, Terada Y, Nakamura S, Chillik CF, Olmedo SB, Chemes HE. A pathology of the sperm centriole responsible for defective sperm aster formation, syngamy and cleavage. Hum Reprod 2002;17: 2344-2349.

Rives NMD (2005). Chromosome abnormalities in sperm from infertile men with normal somatic karyotypes: asthenozoospermia. Cytogenetic and Genome Research 111 172-176.

Said TM, Agarwal A, Sharma RK, Thomas AJ, Sikka SC: Impact of sperm morphology on DNA damage caused by oxidative stress induced by beta-nicotinamide adenine dinucleotide phosphate. Fertil Steril 2005, 83:95103.

Salisbury, J. L., Baron, A. T., Coling, D. E., Martindale, V. E., \& Sanders, M. A. (1986). Calcium-modulated contractile proteins associated with the eucaryotic centrosome. Cell motility and the cytoskeleton, 6(2), 193197.

Santiso R, Tamayo M, Gosálvez J, Meseguer M, Garrido N, Fernández JL: Simultaneous determination in situ of DNA fragmentation and 8- oxoguanine in human sperm. Fertil Steril 2010, 93:314-318.

Sarrate Z, Vidal F, Blanco J. Role of sperm fluorescent in situ hybridization studies in infertile patients: indications, study approach, and clinical relevance. Fertil Steril 2010;93:1892-1902.

Schatten H, Sun QY. The role of centrosomes in mammalian fertilization and its significance for ICSI. Mol Hum Reprod 2009;15:531-538.

Schatten H. The mammalian centrosome and its functional significance. Histochem Cell Biol. 2008 Jun;129(6):667-86. doi: 10.1007/s00418-008-0427-6. Epub 2008 Apr 24. Review.

Schulte, R. T., Ohl, D. A., Sigman, M., \& Smith, G. D. (2010). Sperm DNA damage in male infertility: etiologies, assays, and outcomes. Journal of assisted reproduction and genetics, 27(1), 3-12.

Sergerie M, Laforest G, Bujan L, Bissonnette F, Bleau G: Sperm DNA fragmentation: threshold value in male fertility. Hum Reprod 2005, 20:3446-3451.

Shi, Q., \& Martin, R. H. (2001). Aneuploidy in human spermatozoa: FISH analysis in men with constitutional chromosomal abnormalities, and in infertile men. Reproduction- 121(5), 655-666.

Simerly C, Zoran SS, Payne C, Dominko T, Sutovsky P, Navara CS, Salisbury JL, Schatten G. Biparental inheritance of gamma-tubulin during human fertilization: molecular reconstitution of functional zygotic centrosomes in inseminated human oocytes and in cell-free extracts nucleated by human sperm. Mol Biol Cell. 1999 Sep;10(9):2955-69.

Spanò, M., Bonde, J. P., Hjøllund, H. I., Kolstad, H. A., Cordelli, E., \& Leter, G. (2000). Sperm chromatin damage impairs human fertility. Fertility and sterility, 73(1), 43-50

Sun, X., Ma, J., Ge, Y., Li, S., Yu, Z., Xue, S., \& Han, D. (2002). Abnormal expression of centrosome protein (centrin) in spermatozoa of male human infertility. Chinese Science Bulletin, 47(10), 822-823.

Sun, Y., Vestergaard, M., Christensen, J., Zhu, J.L, Bech, BH., Olsen, J. (2007) Epilepsy and febrile seizures in children or treated and untreated subfertile couples. Hum Reprod, 22:215-20.

Tandara, M., Bajić, A., Tandara, L., Bilić-Zulle, L., Šunj, M., Kozina, V., Jukić, M. (2014). Sperm DNA integrity testing: big halo is a good predictor of embryo quality and pregnancy after conventional IVF. Andrology, 2(5), 678-686.

Tang SS, Gao H, Zhao Y \& Ma S 2010 Aneuploidy and DNA fragmentation in morphologically abnormal sperm. International Journal of Andrology 33 e163-e179

Tempest HG \& Griffin DK 2004 The relationship between male infertility and increased levels of sperm disomy. Cytogenetic and Genome Research 107 83-94.

Templado C, Hoang T, Greene C, Rademaker A, Chernos J, Martin RH. Aneuploid spermatozoa in infertile men: teratozoospermia. Mol Reprod Dev 2002;61:200-204.

Terada Y, Hasegawa H, Takahashi A, Ugajin T, Yaegashi N, Okamura K. Successful pregnancy after oocyte activation by a calcium ionophore for a patient with recurrent intracytoplasmic sperm injection failure, with an assessment of oocyte activation and sperm centrosomal function using bovine eggs. Fertil Steril. 2009 Mar;91(3):935.e11-4. doi: 10.1016/j.fertnstert.2008.09.043. Epub 2008 Nov 14.

Vahab Saadi, A., Kushtagi, P., Gopinath, P. M., \& Satyamoorthy, K. (2010). Quantitative fluorescence polymerase chain reaction (QF-PCR) for prenatal diagnosis of chromosomal aneuploidies. International Journal of Human Genetics, 10(1-3), 121-129.

Van Blerkom, J. (1996). Preimplantation embryology: Sperm centrosome dysfunction: a possible new class of male factor infertility in the human. MHR: Basic science of reproductive medicine, 2(5), 349-354.

Varghese AC1, Bragais FM, Mukhopadhyay D, Kundu S, Pal M, Bhattacharyya AK, Agarwal A. Human sperm DNA integrity in normal and abnormal semen samples and its correlation with sperm characteristics. Andrologia. 2009 Aug;41(4):207-15.

Vegetti W, Van Assche E, Frias A, Verheyen G, Bianchi MM, Bonduelle M, Liebaers I, Van Steirteghem A. Correlation between semen parameters and sperm aneuploidy rates investigated by fluorescence in-situ 
hybridization in infertile men. Hum Reprod 2000;15:351-365.

Walter Vegetti, Elvire Van Assche, Alexandra Frias, Greta Verheyen, Massimiliano M.Bianchi, Maryse Bonduelle,Inge Liebaers and Andre Van Steirteghem. Correlation between semen parameters and sperm aneuploidy rates investigated by fluorescence in-situ hybridization in infertile men. 2000 Human Reproduction vol.15 no.2 pp.351-365

Zini A, Fischer MA, Sharir S, Shayegan B, Phang D, Jarvi K: Prevalence of abnormal sperm DNA denaturation in fertile and infertile men. Urology 2002, 60:1069-1072.

Zini, A., Bielecki, R., Phang, D., \& Zenzes, M. T. (2001). Correlations between two markers of sperm DNA integrity, DNA denaturation and DNA fragmentation, in fertile and infertile men. Fertility and sterility, 75(4), 674-677. 